\title{
Light-zone(s): as Concept and Tool
}

Merete Madsen, The Royal Danish Academy of Fine Arts 


\begin{abstract}
Daylighti is essential to the experience of an architectural space. Nevertheless, amongst the handful of predominantly scientific methods available to assess daylight in architecture, there are only a few considering the spatial and form-giving characteristics of daylight.
\end{abstract}

This paper investigates light-zone(s)ii as concept and tool, which can be taken as a point of departure for a new method to perceive, consider and analyse daylight in architecture.

As concept, light-zone(s) are areas, fields or zones of light. It is a way of considering a space's daylight as (forms of) bubbles or spheres of light, which as light-zones can be compressed, expanded, combined, exploded, etc., all according to the character of 'the meeting' between the light-zone(s) and the space itself (inclusive of the space's content). Thus, the daylight in a space can be regarded as a composition of light-zones.

As tool, light-zone(s) are (spatial) groupings of the lighting variables (intensity, direction, distribution and colour), which are significant to the space and form-giving characteristics of light. That is to say, the light-zone(s) tool is the point of departure for a method of creating a spatial 'grasp' on daylighting variables in a given space.

The relation between the light-zone(s) concept and tool respectively can be described as follows: On the one level light-zone(s) can be explored as an architectural idea or notion, thus belonging more to the field of architectural theory. On another more practice-driven level, light-zone(s) can be articulated and specified in relation to lighting technology.

\section{Introduction}

How do architects actually assess the spatial and formgiving qualities of daylight in their design processes? Probably this is done in many different and personal ways. Intuition, imagination, and experience are presumably important drivers. Design proposals might subsequently be explored in physical (scale) models and digital models alike.

Without elaborating further on the architectural design process, the architectural assessment of the spatial and form-giving qualities of daylight can be said to be based on a combination of thoughts and visual representations of daylight. In this context, the word 'thoughts' should be understood as a way of working with light as an impalpable matter, or as the Light \& Space artist James Turrell explains it: "A lot of the learning to work with light, since it doesn't form by working with the hands as clay does, is this working with light through thoughts"iii.

It is in general the field of architectural theory that offers thoughts about light and space. Yet, this is mainly done on a conceptual level where a space's daylight are more or less understood and described as entities. It is not within the field of architectural theory to analyse the detailed effects of the spatial and form-giving characteristics of daylight.

Contrary to architectural theory, lighting technology offers an instrumental and quantitative determination of the lighting variables which are significant to light's spatial and form-giving characteristics. This is traditionally based on calculations measured at specific points within the space.

There is quite a gap between the approaches and methods of architectural theory and lighting technology. This is particularly problematic in assessing the spatial and formgiving characteristics of daylight, because it means a great deal of knowledge is not being merged into the architectural design practice.

The aim of the light-zone(s) concept and tool is therefore to establish a mediating platform between the fields of architectural theory and lighting technology. It is proposed that this can be done by analysing the daylighting entitiy in a space and dividing them into light-zones, as well as suggesting means or approaches to consider quantifiable measures or descriptors and group them to be congruent with these light-zones.

\section{Light-zone(s) as Concept}

The light-zone(s) concept is a proposal for an architectural idea or notion, which can be taken as a point of departure for a new method of perceiving, considering, and analysing daylight in architecture: a method that sees the daylight of a space as (forms of) bubbles, spheres or zones of light.

The starting point for a description of the light-zone(s) concept is the notion of an antipode. Conceptually this should be zones of darkness. The problem about that is that the word 'darkness', at least in a western context, has become to be understood as something absolute, whereas the word 'light' is understood in a broader sense. The idea of a light-zone created and surrounded by darkness works well in a description of a campfire at night, where the light- 
zone of the fire is "encircled by 'walls' of darkness"iv, but it would be misleading to use the word 'darkness' in relation to most modern spaces, because darkness is rarely present in modern (Western) architecture. In the everyday language of architecture light is generally opposed to shade or shadow. Theoretically this is wrong, because it implies only part of the compositional spectrum available, and because of the fact that the idea of something that is 'light only' is as visually blinding as (our contemporary understanding of) darkness.

Nevertheless, this paper will use an everyday language and describe the daylight of a space as it is perceived. This means that light-zone(s) might be opposed to 'shadowzone(s) in relation to a particular space, but that doesn't mean that shadow-zone(s) are antithesis. It simply means there are no real dark areas in that particular space.

The spatial and form-giving characteristics of light-zones and darkness-zones can be described as follows: Lightzones create areas, places or zones to be in, whereas zones of darkness create thresholds and transition zones. The composition of light-zones and darkness-zones also change the appearance of a space. Perceptually, bright surfaces seem to advance and expand in space, while darker areas seem to diminish and shrink. Furthermore, the daylight of a light-zone has the potential of 'revealing' space, form, and matter, whereas deep shadows and darkness conceal. Consequently, the form-giving characteristics of daylight as exposing matter can be related to light-zone(s), while darkness-zone(s) only suggests space, forms, and matter- a quality that animates our imagination (for better or for worse).

The second point for an explanation of the light-zone(s) concept is the relation between daylight and a given space. Light and space are naturally inseparable, but conceptually you can focus on a space's daylight in order to analyse the effects. For instance, if there is a large dark barn with one daylight opening only, this opening will create a light-zone. The light-zone's intensity as a 'field of energy'v will depend upon the size, shape/form and placement of the opening, as well as the attributes of the space's illuminated surfaces. If the opening is modified, the light-zone would change as well, but the light-zone could also be changed by altering the illuminated surfaces. Say there were some columns around the light-zone. If these columns were moved closer to the light-zone's centre, the light-zone would gain 'energy' and appear more intense. On the contrary, if the columns were pulled further away, the light-zone would decrease in energy and 'loosen up'.

The third point for an account of the light-zone(s) concept is to consider the daylight that a light-zone holds as a 'potential' (to be revealed). The explanation of this follows as a short story about of a photograph of the eastern cloister in Le Thoronet Abbey in southern France (fig. 1). In the picture, there are some bright spots on the cloister floor,

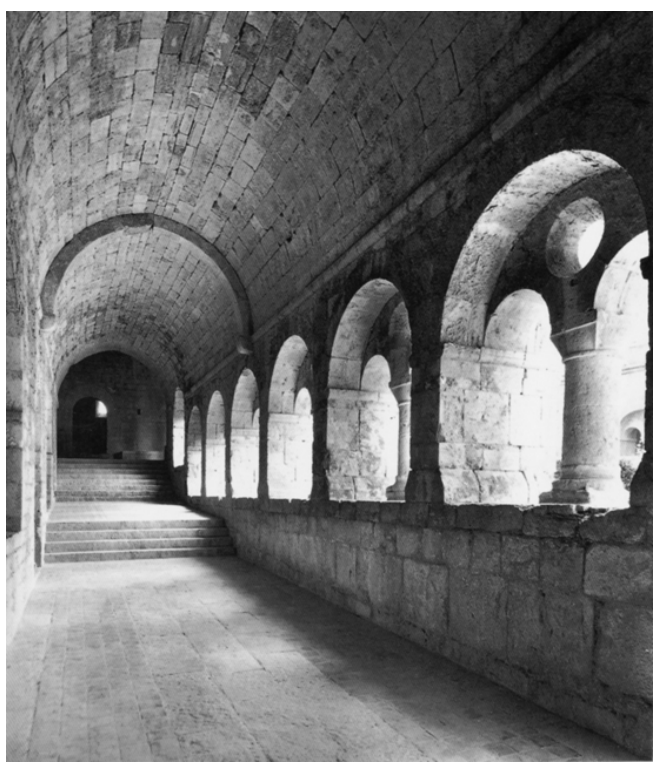

Fig. 1. Light-zone(s) holds light as a 'potential'. Eastern cloister (walkway) in Le Thoronet Abbey. Photo Credit: Zodiaque

one for each opening. These illuminated spots bear witness to the light-zones which exists as potential(s) in the space. Imagine if you will, a monk, in his flowing white hooded robe, entering the cloister walkway around the back corner, stepping out of the shadow at the top of the stair and being 'put into the limelight' by the raised landings relatively intense light-zone. As he would move further through the walkway, his movement would be marked by a rhythm of light and shade. He would expose a sequence of lightzones, but he would, as illuminated matter, only expose one light-zone at the time. Imagine his face and how it would change.

The phenomenon of light-zones 'emerging' and 'vanishing' explains the phrase that light-zones hold light as a 'potential'. The poetical potential of light-zones is that they are ephemeral. 


\section{Light-zone(s) as Tool}

The light-zone(s) tool facilitate the analysis of a space's daylight in further detail. The purpose of the light-zone(s) tool is to integrate predictability into the conceptualisation of light-zone(s), and to make connections to more detailed

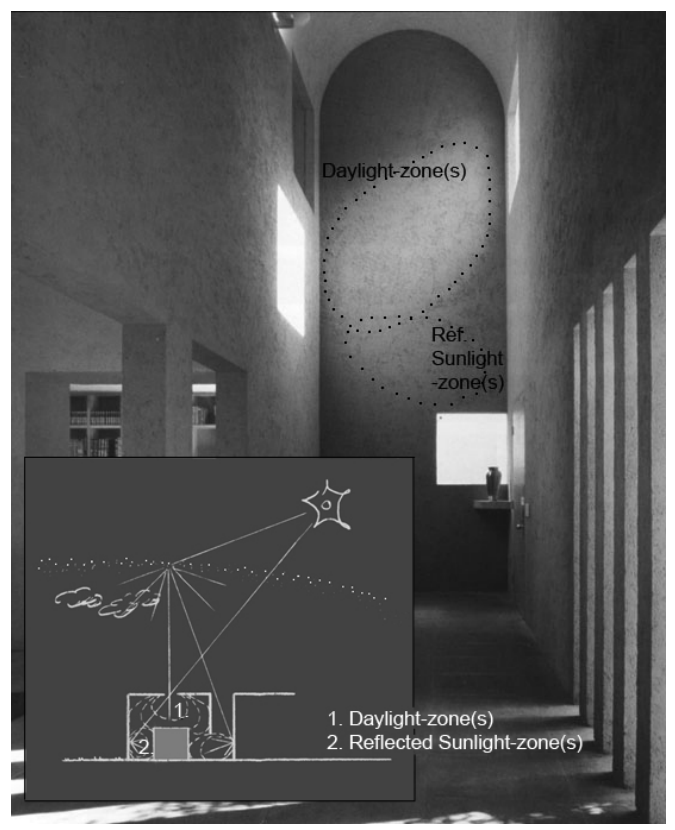

Fig. 2: Daylight-zone(s) [light zone(s)] and reflected sunlight-zones. Legorreta

Arquitectos 'Tec House', Mexico. Photo

Credit: Lourdes Legorreta, with additional text and drawings by Merete Madsen

assessment methods within the field of lighting technology. Thus, the aim is to develop light-zone(s) to a stage where they can function as an instrumental tool as well as a conceptual design tool.

In order to specify the light-zone(s) tool, the light-zones must be set in relation to the light source (Fig. 2). In this paper two forms of light-zones are designated: daylightzones (created by direct daylight from the sky) and reflected sunlight-zones, (created by sunlight reflected from by a non-mirroring surface). Additional light-zones could be designated, in principle each time light is reflected off a surface that alters the light's characteristics, but that is beyond the scope of this paper.

When analysing the daylight of a space by means of the light-zone(s) tool, the entities of daylight are divided into light-zones. As a point of departure, each daylight opening creates one light-zone, but there are no fixed limits as to the number of light-zones a particular space can be divided into. This always depends on the space.

The methodology for working with the light-zone(s) tool is proposed to be a graphical representation of the daylight in plan and section (Fig. 4). The graphic representation of the quantitative distribution of daylight in a plan drawing is commonly used within the field of lighting technology, but the tools for calculating and illustrating light-zone(s) in section are currently missing.

The sections presented in this paper have been calculated and draw by hand, and are thus far too time-consuming. In some lighting simulation programs it is possible to 'flip' the measurement-plane from horizontal to vertical, but this doesn't show the flow of daylight or it's quantitative distribution in section: it illustrates the light upon a fictive (ghosted) wall surface. The method for drawing light within a section exists vi, but it has yet to be developed into a usable piece of software or incorporated into existing lighting programs.

The reason to illustrate a space's light-zones in plan and section is that they reveal the lighting variables which are significant to the space and form-giving characteristics of daylight within the spacevii, i.e. quantify the daylight which light-zone(s) process as 'potential'.

The representation of daylight in plans and sections are is also the link to more sophisticated assessment methods in lighting technology; such as the 'Scale of Shadows'viii and 'Cubic Illumination'ix. This is both in relation to light-zone(s) as a method for creating spatial 'grasp' on daylighting's variables in a given space, but also because the representation of light-zone(s) in plan and section drawings provides a general idea about the parts of or points in a space which can be positively investigated in further detail.

\section{The Analytical Uses of Light-zones}

In order to investigate the analytical use of light-zones, the following two spaces have been studied: The lending room in Alvar Aalto's Municipal Library in Rovaniemi in northern Finland [1968] and the foyer in Le Corbusier's own apartment in Paris [1934].

These spaces have been chosen for two principal reasons. Firstly they represent an investigation method that start with 
a 'simple' case, where the light-zones are defined individually by being separated by a shadow-zone (Aalto's library) and end with a 'complicated' case study, where the light-zones are merged (Le Corbusier's foyer).

The second reason for choosing to focus on these spaces is that they exemplify enduring works of modern architecture.

Finally, it should be noted that the analyses have been conducted on a principally conceptual level, based upon my explorations and observations on-site, as well as literature investigations and studies.

\section{Alvar Aalto's Municipal library in Rovaneimi $\left[66^{\circ} \mathrm{N}\right.$ ]}

The distribution of daylight is fairly uneven in the lending room of Aalto's library in Rovanimi. The varying daylightlevels mean that the space's light-zones are defined individually and perceived as special kinds of 'rooms within the room' (fig. 3).

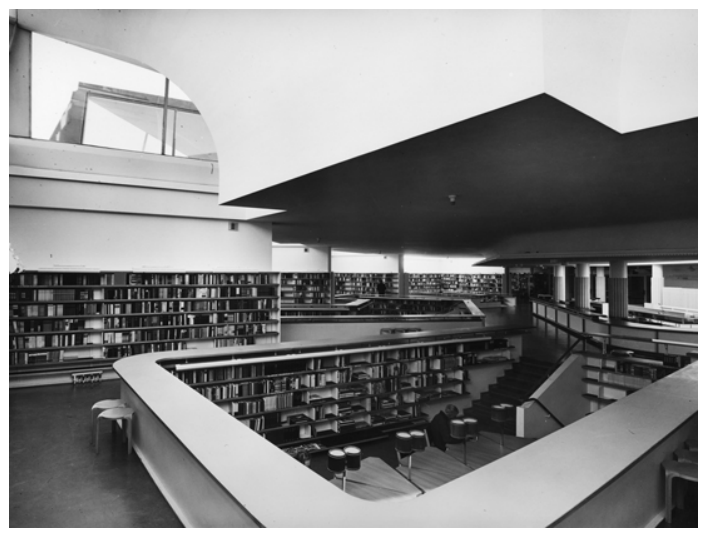

Fig. 3. The lending room in Alvar Aalto's Municipal Library in Rovaniemi, Finland. Photo Credit: Simo Rita.

The library is 'unusual' in two ways: Firstly Rovaniemi is situated in northern Finland (at the polar circle), where the presence of daylight is as much an annual as a diurnal phenomenon and the twilight periods are long, varied, and rich in colours. Secondly Aalto is mainly known for a delicate treatment of an almost shadowless and soft daylight. The library in Rovaniemi is Aalto's most 'dramatic' daylight composition, but still the light is perceived as soft.

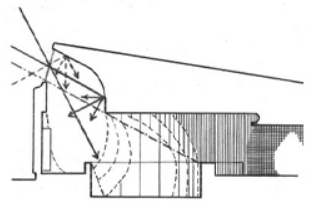

The 'skylight scoop'

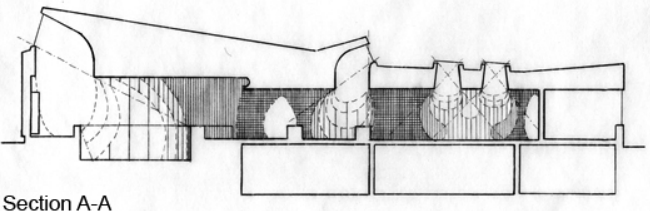

Section A-A

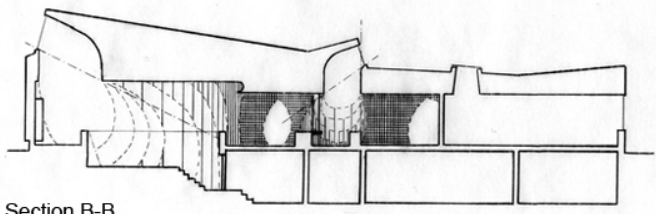

Section B-B

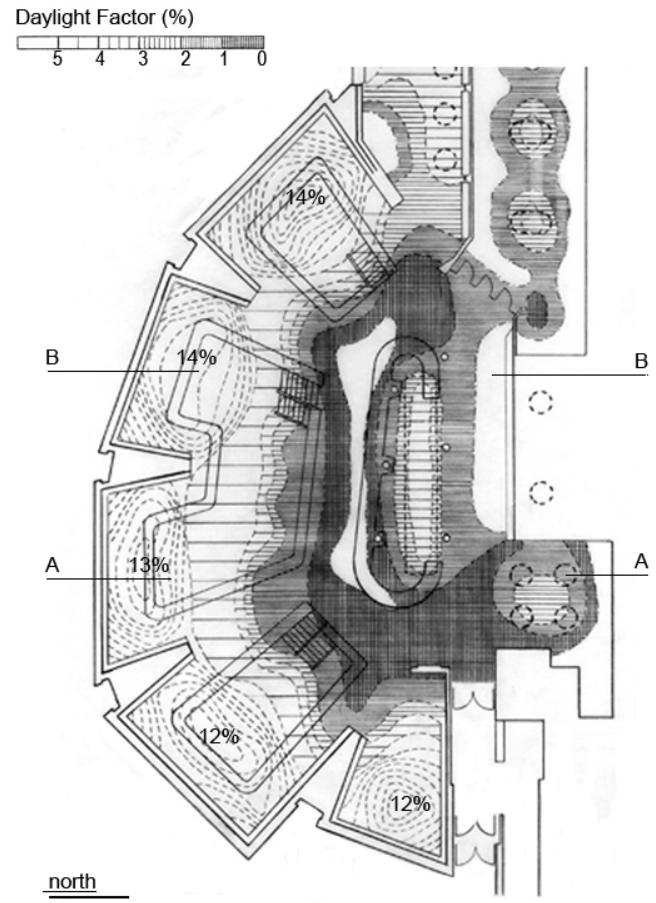

Fig. 4. Plan and sections of light-zone(s). Drawing: Merete Madsen 
The analysis of the library space's daylight resulted in a division into three principal daylight-zones and some smaller artificial light-zones. The daylight-zones will be referred to as light-zones, where as the artificial light-zones will be defined as artificial light-zones.

The three light-zones of the lending room are as follows: One light-zone is created around a central control desk; a series of similar light-zones are created around a row of reading niches along the northern fan-shaped wall; and finally one light-zone is created by four conical skylights above a reading area between the control desk and the back entry (Fig. 4). This paper will focus on the two first mentioned light-zones and only take the last one into account in relation to the lending room's overall composition of light-zones.

Each of these light-zones relates to a particular function of the lending room. The functions are transformed into an almost ritualistic sequence in which one finds a book (the reading niche's illuminated bookshelves), browses through the book on various levels (the reading niches light-zones), and then borrows the book (the control desk's light-zone). One moves in the transitional shadow-zone.

One enters the lending room toward the control desk's lightzone. Apart from providing a good sense of daylight in the innermost part of the space, the control desk's light-zone accentuates the desk area as the room's centre of circulation. The control desk's light-zone is rather intense, because the direct daylighting is supplemented by reflected sunlight as well as daylighting that is indirectly reflected downward onto the vertical surfaces of the columns.

From the control desk one sees the entire room. At the same time one can clearly perceive the space's light-zones (as 'rooms within the room'). The effect of such individually marked light-zones has most precisely been described by Henry Plummer, who writes: "When a vivid light is encompassed by space it acts as a magnetic centre or node, and when seen in the distance establishes a magnetic axis, the former exerting a centripetal and the later a lineal gravity"x. The function of the intermediate shadow-zones, which limits and defines the light-zones, is thus circulation.

The reading niches along the north wall are illuminated by the 'skylight-scoops'xi that follow the wall's fan-shaped form. These apertures are a hybrid between a clerestory window and a skylight: 'skylight scoops'. The skylight scoops act as 'eyebrows'xii, preventing a direct view to the segment of the sky that could cause glare when seen from the shadowzone. At the same time, the reading niche's light-zones are intensified because the scoops reflect the daylight downwards into the reading niches and onto the vertical surfaces of the bookshelves (Fig. 4, top drawing), which to a high extent define the light-zones.

The light-zones defining the north-facing reading niches have the added refinement of connecting the sunken reading niches with the library's upper level. In other words, the composition of light-zones, as well as a single lightzone, is able to both divide the space as well as to connect different spaces.

In the reading niches, the daylighting is augmented by the bookshelves' artificial lighting and by a row of fixed desk lamps in the sunken reading niches, which create warm 'light-caves'. The combination of the cool daylight-zone, enveloping zones of warmer artificial light, are rich in character - especially at this northern latitude, where the periods of twilight are long and varied.

In front of the control desk, Aalto created an artificial lightzone, where the meeting between the patron and the librarian is embodied in a meting between a daylight-zone and an artificial light-zone. The lending room's precise daylighting composition makes particular demands on the artificial lighting, which is either situated within the daylightzones or inside the transitional shadow-zone. Artificial light is not positioned in the area between light and shadow, where it would eliminate the daylighting composition and the experience of light-zones.

The composition of light-zones in the Rovaniemi library's lending room is thus an example of a space where different light-zones are defined individually. Together the lightzones (and the shadow-zone) create an overall composition, where the light-zones hold the 'functions' of the space and the transitional shadow-zones limits and define the light-zones. The 'de-energised' shadow-zone creates a spatial 'pause' between light-zones.

\section{Le Corbusier's foyer in Paris [ $49^{\circ} \mathrm{N}$ ]}

The foyer in Le Corbusier's own apartment in Paris has been chosen because of the complex composition of light and space. The objective of this analysis is to examine the light-zone(s) concept and tool in relation to a case where multiple light-zones merge, and with that challenge possible limitation of the light-zone(s) concept and tool. 


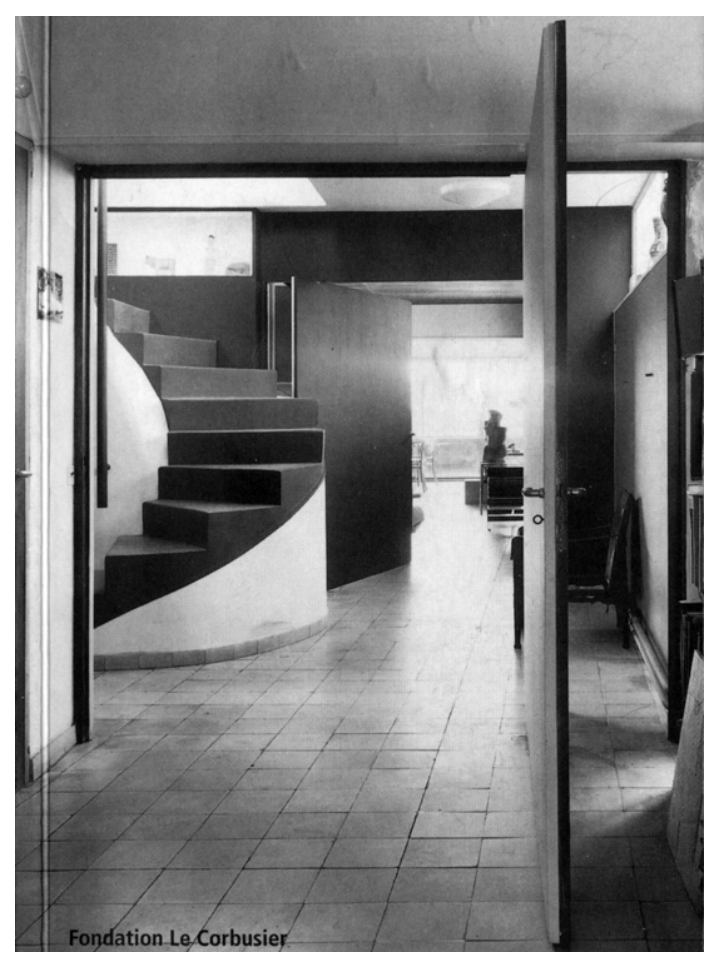

Fig. 5. The foyer in Le Corbusier's own apartment, Paris. Photo Credit: Fondation Le Corbusier

Le Corbusier's apartment consists of three main parts: the atelier towards the east, the dwelling area towards the west, and a top storey with a guest studio and roof garden. The foyer serves as the central link between these three parts (Fig. 5).

One enters the foyer next to a sculptural stairway opposite a blue wall with a long horizontal window. Two large pivoted doors lead from the foyer to the dwelling area and the atelier. The wall and the pivoted door towards the dwelling area are dark brown, as is the back of the door to the atelier. The tiles on the floor are sand-coloured. The rest of the space's surfaces are white, with the exception of the steps that have a dark grey-bluish hue.

At first, the foyer's daylight is perceived as one (fairly uniform) entity of light. That impression can be confirmed by daylight measurements on a horizontal level. However, the space, and in particular the stairway, clearly imply a composition of light and shade.
When analysing the space on the basis of light-zone(s), one can divide the foyers daylight into two principal light-zones: one is created by the long horizontal window, placed at the top of the blue wall; the other is created by a glass pavilion on the top floor (Fig. 6).

The light-zone of the horizontal window illuminates the entire space except the ceiling, the blue wall, the floor area just in front of the blue wall and the risers in the lower part of the staircase.

The light-zone created by the roof pavilion also illuminate most of the space except the ceiling and the upper part of the walls, the staircase's cylindrical base and the risers in the lower part of the staircase.

As a result, the form-giving characteristics of light and shade of the staircase are as follows: the risers are divided into a darker base and a brighter top because the top risers are illuminated by both light-zones, whereas the base risers only receive reflected light from the surfaces of the space. The treads are uniformly lit, mainly by the roof pavilion's light-zone, yet with an evenly decreasing luminance downwards. Finally, the cylindrical base is illuminated from the horizontal window's light-zone, where the main lighting direction is perpendicular to the staircase and thus makes the base's form stand out by means of it being shaded because of its curvature (cosine low).

This composition of space, staircase, and merged lightzones has consequences for the way one moves, as well as the way space and staircase are visually perceived.

The movement can be divided into two axes: a horizontal movement between atelier and dwelling area, and a vertical movement from the foyer to the roof (garden). The horizontal movement is motivated by the light-zones of the horizons towards east and west, while the vertical movement is motivated by the roof pavilion's light-zone from above. The vertical movement varies as one ascends and descends the stairs. The way up is experienced longer than the actual amount of steps one takes, because it is divided into a darker base (that one leaves) and a brighter top (to which one rises). The descent is 'difficult' and slow, as one is 'washed' down the steps towards 'darkness' by the intense light-zone of the roof pavilion. This is emphasized by the fan-shaped sequence of the evenly lit treads which are 'tricky' to distinguish. Of course, the 'lack' of an outer banister doesn't make it quicker. Descending the stairs makes one utterly aware of the bodily movement, 


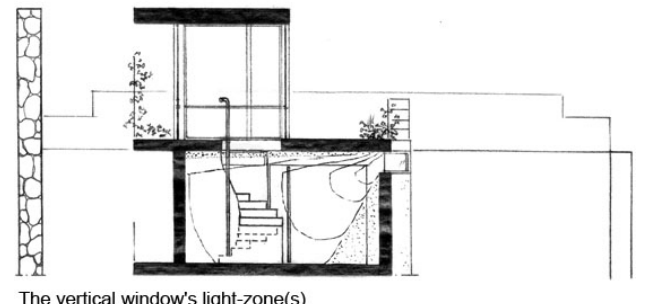

The vertical window's light-zone(s)
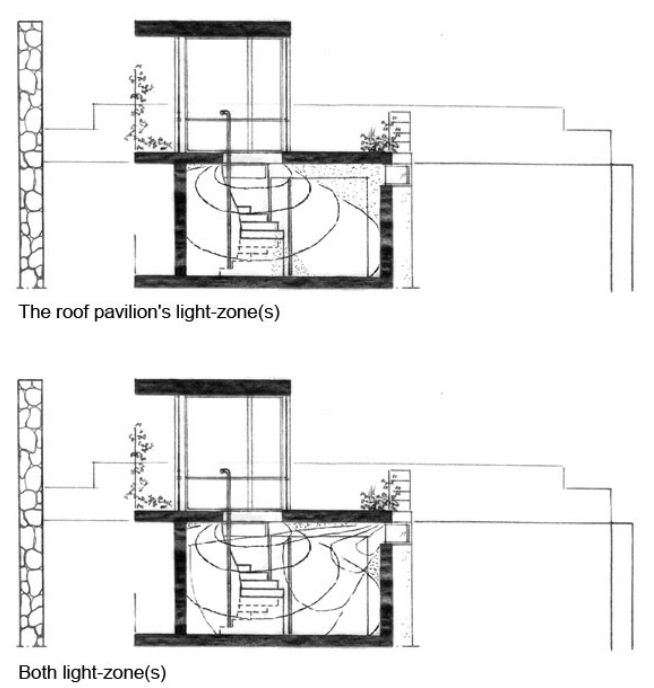

Fig. 6. Sketch of the foyer's light-zones. Calculations and drawings: Merete Madsen.

an awareness that is an important part of the perception of the foyer. Even though the roof pavilion's light-zone makes the vertical axis prominent, the actual physical movement is not straightforward, because the base of the staircase (as one's starting point) is 'hidden away' in the shade.

The 'light-zone of the horizon', which constitutes the horizontal movement, generally has a profane meaning, representing everyday life and rituals. The vertical movement is motivated by the predominantly vertical flow of light from the roof pavilion. A vertical daylighting direction constituting the 'light-zone of the the sky' generally holds a sacred meaning, in this case representing the rising from the foyer's relative dimness to the full daylight and $360^{\circ}$ panorama of the roof garden, that Le Corbusier called his 'meditation space'xiii.

The visual perception of the foyer is equally as refined. Le Corbusier has described his foyer as the origin for his notion of l'espace indicible. More specifically, it was his experience of the foyer with one of his own paintings hanging on the northern wall (at a particular occasion) ${ }^{\mathrm{xiv}}$. I choose to believe that the painting can also be a methodology to see. Le Corbusier can presumably be called a cubist painter. One of the 'effects' of cubism is to represent objects simultaneously from multiple viewpoints, in order to create a perception of 'a/the fourth dimension'. The three-dimensional staircase can be seen in a similar way in reverse. One can see the composition of light and matter as plan, section, and elevation at one glance: The fan-shaped sequence of evenly lit threads as plan; the division of risers as section; and the cylindrical base, with its form-giving shading, as elevation. Such 'effects' are only part of the vivid composition of light, space, and colours. Another is that the top and base of the staircase can, when seen from the atelier, change positions because the brighter top of the staircase seems to advance in space while the darker base perceptually 'diminishes' and 'moves' further away. Thus, the three-dimensional space can turn two-dimensional or relate to other dimensions. However, the foyer's composition can't be observed from one viewpoint only. The experience of the space accumulates as one moves into and through the foyer.

As opposed to the form-giving effects of the merging lightzones on the staircase, the distribution of light on the walls of the foyer is fairly uniform. Here, the lack of form-giving shadows on the wall surfaces emphasizes the colours. It's perceived somewhat like the coloured wall surfaces 'dismantles' and are perceived as purely geometrical figures 'floating' in space according to the perspectives of colours.

The spatial and form-giving characteristics of daylight in Le Corbusier's foyer seem inexhaustible. In relations to the light-zone(s) concept and tool it would be fair to conclude that the merging of light-zones holds a potential to give form to compound objects like the staircase.

This study of Le Corbusiers foyer confirms the thesis that light-zone(s) motivate movement (locomotion) in space. Despite the fact that the foyer's daylight can be analysed as two principal light-zones, the daylight of the foyer acts as a shadow-zone in relation to the light-zones of the dwelling area, atelier, and roof pavilion. This also shows that the light-zone(s) concept is malleable. With reference to the discussion about light-zone(s) vs. darkness-zone(s), the perception of light-zone(s) always depends on adjacent light-zone(s). 


\section{Conclusion and Perspective}

The light-zone(s) concept and tool has two main positions: The one being the analytical application of light-zone(s), and the other being the mediating 'platform', that lightzone(s) establishes between architectural theory and lighting technology.

The analytical use of light-zone(s) offers a point of departure for a new method of perceiving, considering and analysing daylight in architecture.

The case studies presented in this paper represent only a limited set of examples in working with light-zone(s) as concept and tool. They do, however, endeavour to illustrate how daylighting in a space can be regarded as a composition of light-zones. Undeniably, further study needs to be conducted in order to examine the analytical use of light-zones. In particular, there is a need for case studies of contemporary spaces (especially those with an extensive use of glass), as well as of spaces located at lower latitudes.

The analytical application of light-zone(s) could moreover be relevant to lighting-designers, in order to design artificial lighting with greater care and consideration for the composition of daylight.

However, the analytical use of light-zones doesn't provide any answers to the questions about 'lighting quality' as such, nor do different light-zones posses any independent qualities. In that sense the light-zone(s) concept and tool is 'an art of possibilities'. The assessment of qualities is merely a matter of how a particular light-zone or a composition of light-zones fulfils an architectural design concept.

This means that general discussions on daylight qualities in spaces are proposed to be related to an ongoing discussion about architectural qualities within the field of architectural theory. The means to assess the spatial and form-giving characteristics and quantities of daylighting, on the other hand, can be developed within the field of lighting technology.

This is why the mediating 'platform' which light-zone(s) establish between architectural theory and lighting technology, is essential and calls for a diversity of interdisciplinary discussions and collaborations.
The overall perspective of light-zone(s) as mediating 'platform' is thus to merge - or rather to emerge - research, which relates to the spatial and form-giving characteristics of daylight, from the fields of architectural theory and lighting technology, into the architectural design praxis.

\section{Endnotes:}

\begin{abstract}
' 'Daylight' is to be understood as the light from the sky. Lightzone(s): as concept and tool doesn't include direct sunlight. Sunlight is of significant importance to architecture, but in the core of this paper, the direct sunlight is regarded as another 'kind' of light source, that doesn't create light-zone(s).

ii The term 'light-zone(s)' is a translation of the Danish word lysrum, which most immediately can be translated as 'lightspace(s)', or more aptly as 'light-zone(s)'. In the context of this paper, the use of the English word 'zone' - instead of 'space' - offers a more graphically correct depiction of the Danish word rum. Because 'zone' can be used more interchangeably to refer to both abstract (i.e., space) and particular (i.e., place/room) examples. More importantly, the use of the English word 'zone' implies spatiality, and thus a more embodied experience, than does the abstracted term of
\end{abstract} 'space.'

The use of the term 'light-zone(s)' in English can moreover be seen to be related to similar nomenclatures coined by Professor Henry Plummer; where he describes his notions of "sphere of light", "light-field", and "bright zones" under the phrase: "Fields of energy" Cf. Plummer, Henry. 1987. Poetics of light. Tokyo: $\mathrm{a}+\mathrm{u}$ (Architecture and Urbanism), December Extra Edition.

iii James Turrell, interviewed by Esa Laakosonen. 1996.

"James Turrell, Blacksburg, Virginia 1996".

http://home.sprynet.com/ mindweb/page44.htm.

iv Plummer, Henry. 1987. Poetics of light, Tokyo: a+u

(Architecture and Urbanism). December Extra Edition, p. 79.

${ }^{v}$ Plummer, Henry. 1987. p. 75.

${ }^{v i}$ Tregenza, Peter R. 2000. The luminous energy field: a finite element model. Lighting Research and Technology, Vol. 32, No. 3.

vii It might be worth mentioning that the calculation of daylight in a space, which forms the basis of light-zone(s) as a tool, is stated in percentages. That means that the determination of light-zone(s) doesn't oppose the main quality of daylight: which is forever changing.

viii Frandsen, Sophus. 1985. Lyset I rummet og lyset på tingene. Copenhagen: Louis Poulsen, LP NYT, nr. 492. ${ }^{i x}$ Cuttle, Christopher. 2003. Lighting by Design, Oxford, Boston: Architectural Press.

${ }^{x}$ Plummer, Henry. 1987. p. 75

${ }^{x i}$ Madsen, Merete. 2003. An Analysis of the Daylighting

Principles in Two Libraries Design by Alvar Aalto - When a Daylight Opening Functions as 'Daylighting Luminarie'. Proceedings of the Seventh International DOCOMOMO Technology Seminar. Alvar Aalto Vyborg Library -

Technology of Sensations. Copenhagen: The Royal Danish Academy of Fine Arts, School of Architecture, p. 76-82. 
xii Moore, Fuller. 1985, Concepts and practice of architectural daylighting, New York: Van Nostrand Reinhold Company, p. 44.

xiii Madsen, Merete. 2004. Lysrum - som begreb og redskab, PHD Thesis, Copenhagen: The Royal Danish Academy of Fine Arts, School of Architecture.

${ }^{x i v}$ Krustrup, Mogens. 1993. Det uudsigelige rum. Denmark:

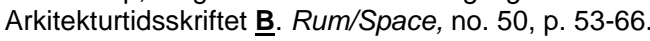

